\title{
Research on development of China E-hailing industry
}

\author{
Xuecheng Wang ${ }^{1, *}$ \\ ${ }^{1}$ North China University of Technology, School of Economics and Management, No.5 Jinyuanzhuang \\ Road, ShiJingShan District, 100144 Beijing, P.R.China
}

\begin{abstract}
E-hailing cars have become an important innovation in transportation operations. The E-hailing originated in the US and has developed rapidly around the world. As a laggard, China has experienced remarkable progress in exploring development period, rapid expansion period and adjustment period. The main reason is that China has a large user base, a sufficient labor force, a good network innovation environment, and a relatively relaxed regulatory environment. The new policy formulated by the Chinese government has caused a relatively large constraint on the Ehailing industry. Whether the E-hailing platform can maintain neutrality business and whether it can safeguarding consumer rights while developing the economy is an important challenge.
\end{abstract}

Key words: E-hailing cars, platform business model, E-hailing industry, development, business

\section{Introduction}

With digital and knowledge-based economy becoming the trend, innovation happens fast due to the interaction between mobile Internet technology and business platforms, in terms of which, e-hailing becomes a good example of the "Internet Plus Transportation" model, reshaping the traffic service market. What's the role of e-hailing platforms in this new industry, or is it possible to create a specific trip market by relocating some resources to match the diversified personal needs with distributed supplies? It's inevitable that economic theories have limitations explaining new phenomenon and sometimes they are divorced from real world, neglecting specific space-time factors.

There's a lot of related research about E-hailing cars. Some researchers found that drivers' collaborative models and evaluation mechanisms at companies such as Uber increase the value of flexible employment [3]. Cramer and Krueger [1] think that Uber has realized the subversive innovation of the taxi industry. A study of Brazil showed that online taxis have replaced a large number of traditional taxis and public transport trips [2]. Vivoda et al. [5] found that the elderly use Internet car very rare, that it is necessary to provide training services for the elderly in order to facilitate their travel. But few people have made research on Chinese E-hailing industries compared with other country.

\footnotetext{
*Corresponding author: wxc@outlook.com
} 


\section{$2 \mathrm{E}$-hailing has become a new trend of business mode}

Uber is usually considered as the originator and typical example of E-hailing service. UberCab was founded in Los Angeles in 2009 and launched the Uber APP in San Francisco in 2010. Passengers can get travel services through this APP, and drivers can meet the passengers' needs and earn income through their own private cars. The generation of online car has its inevitability, because most countries have stricter regulations in the traditional taxi industry [8]. Uber has developed rapidly because it broke the prevailing regulatory difficulties in the taxi industry. Uber offers a variety of services with different prices to meet different travel scenarios. In the three years after the official operation, the average monthly growth rate by over $10 \%$ in an explosive expansion period. Earnest Research estimates that $43 \%$ of people in the past year have use the E-hailing car service from US credit card data.

The Internet travel service represented by Uber has quickly become the most popular innovative business model on a global scale. It has been a model of success in the sharing economy, even named as "Uberification" in other industries. Judging from the development of the global E-hailing platform, Uber has rapidly spread its business to major developed countries with its first-mover advantage, mature information processing capability and operational organization capability, and has achieved market leading position in the United States, Canada, Australia and the United Kingdom. On the other hand, more local companies have joined the model imitation and launched a localized E-hailing car platform. For example, in the Indian market, the Olacabs penetration rate reached $14.4 \%$, much higher than Uber's $4.49 \%$. By the beginning of 2017, online car or similar services appeared in more than 170 countries and regions. According to Bain Consulting's estimates, the global E-hailing car market will reach approximately US\$45 billion in 2016 and is expected to reach US\$72 billion by 2020 [7].

At the end of 2015, the total number of Uber orders reached 1 billion. In 2017, the company achieved a total transaction volume of 37 billion US dollars, with a total order volume of about 4 billion. The number of monthly active users reached 75 million, and the number of active drivers was about 3 million. Uber currently offers a wide range of travel services in 545 large and medium cities in more than 60 countries around the world. In January 2018, Uber received a $\$ 9$ billion investment from Softbank Capital. Uber has accumulated nearly $\$ 30$ billion in financing and has a valuation of $\$ 72$ billion, making it one of the most valuable start-ups in the United States. Uber's biggest competitor, Lyft, also had a total of 375.5 million orders in the US and Canada throughout 2017.

The foreign E-hailing car represented by Uber also faces many development problems. For example, there are insufficient measures for consumer safety protection, and the relationship with the network driver is not clear. The management of problems such as swiping orders and driver picking orders is weak, and there are many conflicts with local policies and regulations. It is difficult for the national E-hailing car platform with a small population to form a network economy effect, and overseas expansion cannot be well integrated with local culture [6].

The E-hailing car model originated in Uber in the United States, and it has evolved from concept to mature product in the United States. However, from the development status quo, China's E-hailing car market has become a global model. China's E-hailing car market capacity, major platform enterprise orders and penetration rate among the people are far better than foreign countries. By the end of 2017, the total number of Chinese netizens reached 772 million, and the total population penetration rate reached $55.8 \%$, higher than the global average (51.7\%) and Asian level (46.7\%), including 753 million mobile phone users, accounting for $97.5 \%$ of the total number of Internet users. The number of listed Internet companies in China and abroad has reached 102, with a total market value of 8.97 trillion yuan; and a total of 77 unicorn companies [7]. From the perspective of global Internet 
development, the number of Internet users has exceeded 3.4 billion, and has maintained a relatively fast growth rate for many years [4]. With the proliferation of the Internet, especially the mobile Internet, the information age has developed rapidly at a rate that no one in the past can match.

Uber entered China as early as February 2014, invested more than 20 billion US dollars in more than 60 cities, and launched the first UberX in China to compete with the traditional taxi industry. In its heyday, China's top five cities with the highest turnover in Uber, China occupied three seats, and Chengdu once replaced New York with the top spot. In August 2016, Uber reached a strategic cooperation agreement with Didi, and Uber officially withdrew from the Chinese market. Some scholars attribute Uber's failure in China to cultural and environmental adaptability [6]. For example, Uber discount codes are far less acceptable to consumers than WeChat red envelopes. Uber insists on using email customer service and cannot respond quickly to consumer complaints. However, from the internal reasons, the Ehailing car platform represented by Didi can fully tap the unique elements of China's economic development, accurately grasp user needs, flexibly organize supply, and play a more important role in achieving bilateral matching.

The aim (importance) of this study can be concluded on two levels, the first being the practical meaning that it can increase the understanding of E-hailing industry and provide references for the operation of Information platforms as well as the management efficiency for governments; and the second being the theoretical meaning that it can enrich the scope of economic interpretation in terms of supply-demand relations and provide support for innovative study on the way of market organizing under the background of digital and knowledge-based economy.

\section{Results}

\subsection{The development of China's E-hailing car}

China's E-hailing car has experienced three relatively obvious development stages: before 2013, it was the exploration and development period of the E-hailing car, and the offline car rental company represented the development of the Internet; from 2013 to 2015 , it was the E-hailing car. During the rapid expansion period, the network of car travel services continued to improve, the number of users increased sharply, and the market response was fierce. In the second half of 2015, the E-hailing car ushered in the adjustment period, the central and local policies were introduced, and the E-hailing car industry entered. As the threshold increases, the platform assumes more regulatory responsibilities.

\section{1) Exploring period}

As early as around 2006, car rental companies took the lead in trying to integrate with the Internet. Car rental companies such as car rentals and car rental companies in China are digitally transforming business processes such as vehicle information release, user reservation, and process auditing while developing offline service outlets. At this stage, there has not been a real platform enterprise, but it has laid the foundation for platform development. In 2010, the company was established in Beijing, and Dongfang Cheyun Information Technology Co., Ltd. was established. Easy to get is the first company to organize travel service resources as an Internet information company, focusing on business travel, and vehicles mainly from offline car rental companies. It is easy to position itself as a platform to provide comprehensive services for users, vehicle leasers and drivers. By August 2012, it was easy to integrate nearly 5,000 vehicles.

In August 2012, Didi's taxi software was launched. This type of mobile APP first focuses on the car business of traditional taxis. Passengers can call the taxi quickly and conveniently 
through the APP, and the driver can also conveniently take orders through the APP and increase revenue by reducing the no-load rate. The emergence of taxi software optimized the traditional taxi travel service, which is helpful for solving the problem of difficult taxis, but there is no fundamental improvement. After a difficult push stage, the taxi software won the first batch of stable users, and was recognized by the market. The number of users has increased dramatically. It has become a new thing for public opinion to report, and it has become an excellent target for venture capital and capital markets. The taxi software is a typical intermediary platform. It only provides information services, which combines the supply and demand of taxis, and has obvious characteristics of light asset operation.

\section{2) Rapid expansion period}

In 2013, it was called the first year of mobile Internet. The mobile communication base station was integrated into the network. The wlan network technology was mature, the commercialization of LBS technology was mature, and the cost of smart phones continued to move down, which created a good foundation for the development of mobile Internet technology. At the commercial practice level, mobile phone shopping and mobile payment have matured. The $\mathrm{O} 2 \mathrm{O}$ platform has reached the Internet outlet, and a large number of online and offline platforms have emerged.

Driven by platform companies, innovative products in various segments of the travel market continue to emerge. The appearance of the special car marks that the Internet App is not only an auxiliary tool for the taxi industry, but also a competitor that cannot be ignored. In July 2014, the fast taxi announced the launch of the new business brand "No. 1 Special Vehicle" targeting mid- to high-end users. Didi also launched a special car in August 2014, targeting the mid- to high-end business car group. Special vehicles have higher requirements on the value of vehicles, and drivers also need to undergo standardized business etiquette training to get on the job. While the car has gained widespread praise in the market, Didi continues to improve its product line. In 2015 alone, direct shuttle buses, express trains, shuttles, buses, drivers and chartered vehicles were launched. It provides a wide range of alternative products for different travel preferences, covering the entire field of daily travel of residents.

At this stage, the competition between the network and the car platform has become more intense. Didi and fast have achieved market leading position, launched a subsidy war, and the market has also spread rapidly. The participation of capital provided support for the subsidy war, and both companies received hundreds of millions of financing. After the subsidy war, the rapid development stage of the E-hailing car market was basically completed, and the capital force contributed to the merger of Didi and the fast. The two occupied more than $80 \%$ of the market share of the E-hailing car industry and achieved a strong market monopoly.

At the policy level, most local governments have adopted a form of informal interviews and seminars to convey the attitude of strict management of online vehicles; a few local governments such as Shanghai and Hangzhou have begun to carry out standard management work. The Ministry of Transport also tends to manage the E-hailing car strictly, but due to concerns about policy uncertainty, it has not rushed to introduce a new deal for the car, and has experienced a long wait-and-see period.

In 2015, the total number of users in the online car market was approximately 294 million. The total number of orders per year reached 1.43 billion, which is nearly twice the number of all taxi orders in the United States in 2015, surpassing the cumulative number of orders Uber has established since its establishment six years ago. 


\section{3) Specification period}

With the rapid development of the travel service platform, the network of car products has been continuously enriched, especially the launch of express trains and express trains. Compared with traditional taxis, the service quality is high while the price advantage is obvious. It has fundamentally touched the interests of the traditional taxi industry, and the conflict between the old and new formats has intensified. Local taxi drivers' strikes and protests have occurred from time to time and have become an important hidden danger affecting social stability.

The Ministry of Transport has accelerated the development of the taxi industry reform and the development of E-hailing car management methods. On July 27, 2016, the Ministry of Transport, the Ministry of Industry and Information Technology, the Ministry of Public Security, the Ministry of Commerce, the State Administration for Industry and Commerce, the General Administration of Quality Supervision, Inspection and Quarantine and the National Network Information Office jointly promulgated the Interim Measures for the Administration of Online Appointment of Taxi Management Services (hereinafter referred to as "Interim measures"). China has thus become the first country in the world to recognize the legal status of the E-hailing car. Since then, the Ministry of Transport has successively established a comprehensive management system from the platform to the driver and the vehicle.

The New Deal of the Internet has given local governments the right to formulate detailed rules for local conditions. In October 2016, first-tier cities such as Beijing, Shanghai, Guangzhou, and Shenzhen took the lead in publishing the draft guidelines for the implementation of the rules for the implementation of the network. Compared with the relatively loose conditions of the Ministry of Transport, the standards for vehicles and drivers for the network were greatly improved. This move has caused widespread dissatisfaction among the public. The main E-hailing car platforms have indicated that the local rules are too strict. Driven by the first-tier cities, the major cities in the country have formulated strict implementation rules, and the development of the E-hailing car industry has been hit hard. Many legal experts have questioned the legitimacy of the establishment of administrative licenses in local areas. Some economists have also questioned whether local implementation rules can promote the healthy development of the industry. At the platform level, the Ehailing car platform gained legal status after the introduction of the national policy and ushered in the golden age of standardized development. However, following the introduction of the local rules, the vehicles and drivers available on the E-hailing car platform fell off the cliff. The heavy asset platform based on the B2C model is relatively less affected by local rules, while the $\mathrm{C} 2 \mathrm{C}$-based light asset platform faces a huge test. In order to gain long-term competitive advantage, the platform has made a fuss about internal management, strengthened the management of E-hailing car drivers, and improved consumer safety protection measures.

As of December 2017, the number of domestic and express passengers has reached 236 million, an increase of $40.6 \%$ over the previous year. Take Didi as an example. In 2017 , more than 20 million drivers and various vehicles access the platform. The annual order volume was 7.43 billion, and the daily order volume was 25 million. The daily order volume of taxis reached 15 million. The average daily car is 6 million, and the daily average is 500,000, and the daily processing data reaches 4,500 TB. Didi Travel has become the dominant player in the global travel service platform, and has expanded to foreign markets through mergers and acquisitions. Didi's vision is to use DDT to become the world's largest one-stop travel platform for ten years, serving 2 billion users worldwide and meeting $50 \%$ of travel needs of consumers. 


\subsection{Why China E-hailing car development well compared with other countries}

China's Internet economy innovation and development has a unique economic and social environment. The E-hailing car platform can adapt to the trend of the times, seize the crux of the Chinese travel industry, and make full use of the convenience of the digital economy to achieve relatively significant results. In the development process of China's E-hailing car platform, there are the following outstanding external advantages:

1) China has a large-scale and huge potential online consumer market. As of 2017, the total number of Internet users in China has reached 770 million, more than one-fifth of the global total. China's Internet consumption reached US\$96.7 billion in 2016, only slightly lower than the US. China's Internet development has a strong stamina. Compared with developed countries, there is still about $30 \%$ of the Internet penetration rate. In addition, from the perspective of the proportion of the Internet economy in terms of overall GDP, China is as high as $6.9 \%$, ranking second in the world [9].

2) China's abundant labor supply during the transition period is an important driving force for the rapid development of the network. The development of the E-hailing car is basically consistent with the period when the Chinese economy entered the "new normal". The traditional manufacturing capacity has released a large amount of labor, and the E-hailing car platform has absorbed a large number of low-cost labor, which has overcome the bottleneck resource constraints of the service industry development. China's Internet marketing promotion is good at combining with the tactical ground promotion of the sea, and the expansion speed is very fast. The labor-intensive matching supporting industries such as logistics, terminal distribution, and manual customer service fully enjoy the demographic dividend and ensure a stable and low-cost operating environment for the Internet platform.

3) China has a sound Internet application innovation system. From the perspective of innovation, China's innovation in Internet application is significantly ahead of the United States and other countries. Crunbase global unicorn company list shows that $90 \%$ of China's listed companies belong to application-driven innovation; from the large Internet enterprise platform Look, the Internet giants represented by Tencent, Alibaba and Baidu provide information flow, capital and other resources for the online car. From the perspective of Internet ecology, China has the most complete network payment and personal credit service system with LBS. A large number of free underlying service support, with intensive offline service sites.

4) China's open Internet innovation supervision provides an inclusive development environment for network vehicles. China regards the "Internet Plus" action plan as a national strategy and attaches great importance to the development of the digital economy. Compared with major developed countries such as Europe and the United States, the Chinese government has provided a relatively long observation period for the development of new Internet things. The government mainly manages through informal channels such as interviews, and can collect various sectors of society before formulating laws or industry management policies. Comments and opinions. The imperfections of the legal and policy systems provide a late-comer advantage for innovation [10].

After study the city transportation service system, this paper divides city transportation into four categories: public transport, sub-public transport, sub-private transport and private transport. It's obvious that current policies that encourage public transport while restrain private transport have caused many problems in sub-public transport systems, driving taxi industry into the dilemma of quantity and price restrictions, bringing about a great shortage of sub-public transport supply. As a supplement for public transport, E-hailing service has become a significant supply, replacing private cars while competing with taxies to solve the problems with market-oriented ways.

E-hailing platforms combine business platforms with mobile Internet technology, responding to specific demands with efficiency. After the space-time redundant analysis, it 
can be concluded that E-hailing service can reduce space-time redundancy without increasing distinct cost. It provides a virtual operation platform for drivers and cars, with a virtual occupation and virtual space-time arrangement, which is more flattening with simplified participants and business model. This platform maintains its order by eliminating the badbehaved drivers and provides comment section for distribution reference to meet customers' demand to the maximum extent, which can also affect drivers' income due to specific algorithm. This real-time distribution mechanism is more flexible and it can encourage drivers to provide better services. This mechanism matches platform with capital, promoting innovation gradually and it has no motivation for monopoly from inside. However, there may be pressure from outside for potential monopoly.

China has issued comparatively easing policies on E-hailing services, but many problems appeared during the implementing of these policies by local governments. After the empirical analysis of local enforcement regulations, we find that randomness and restrictions are very common, without thorough consideration of residents' demands and traffic supplies. This causes obstacles for the development of Information platforms and platforms focusing on capitals appear on the contrary, which goes against China's reform on the increase of transportation models and the activation of assets. Bureaucracy and profit-oriented organizations stage a comeback, restricting the E-hailing platforms and reducing diversified virtual organizations, failing to meet residents' demand in the end. Thus, this paper suggested that Chinese government shall enhance unified management overall profit-oriented cars and implement new E-hailing policies nationwide.

\subsection{Challenges that E-hailing faced in the future}

However, we should also see the many challenges faced in the development of the E-hailing car platform, including external policy pressures, including how to adapt to the platform role, balance the difference between supply and demand, and fulfill the social governance function beyond the economic matching function. The main challenges and bottlenecks include:

1) The E-hailing car policy have limited the economics of platform. The foundation of the platform economy is the market spirit of "free choice". There is no absolute freedom. Any economic action must be established under certain management and control. The original intention of the E-hailing car policy was to safeguard consumer rights and regulate the industry's competitive order. However, in terms of actual development, in different regions, the competent authorities of the industry have different goals and different ways, and the effects of implementation are different. On the whole, most cities have implemented strict management, which forms a constraint on the economic nature of the E-hailing car platform.

2) As a matching organization, the E-hailing car platform should keep neutral. However, as the market scale expands, the industry standard requirements increase, and the power of the E-hailing car platform expands. Almost all E-hailing car platforms are involved in pricing. The function of bargaining through the platform is compressed. Most platforms charge commissions, management fees and other methods are more concealed, and the proportion in the price formation structure has not decreased significantly. Part of the platform that concurrently operates $\mathrm{B} 2 \mathrm{C}$ and $\mathrm{C} 2 \mathrm{C}$ services also has the problem of opaque and unfair distribution mechanism.

3) The platform not only undertakes the function of economic matching, but also undertakes social functions such as safeguarding consumers' lives and property, maintaining information security and protecting privacy. Due to the ineffective review of the E-hailing car platform and the imperfect security system, many vicious incidents of passengers' life and property safety have been violated, which has had a serious negative impact on the credibility of the E-hailing car. In terms of information security, in May 2015, China's Internet vulnerability exposure platform, Wuyun.com released 59 security vulnerabilities 
about taxi software, involving as many as nine manufacturers. In 2016, a serious data breach occurred in Uber, with the name, email and phone number of 57 million passengers, and the names and driver's license numbers of about 600,000 American drivers leaked. Whether it is possible to establish a comprehensive and reliable safety management system has become a sword hanging on the head of the E-hailing car platform.

\section{Conclusion}

The E-hailing platform has shaped a new travel service market. The E-hailing platform under the participation of capital can cultivate the economic habits of both the supply and demand sides through subsidies, quickly reach the basic market capacity required for the platform economic development, and change the life cycle of the Internet platform enterprises. From the perspective of matching expansion, the E-hailing platform is based on its own diversified elements, and conducts rapid trial and error to achieve continuous and incremental innovation in business development. From the perspective of matching monopoly, the E-hailing platform has the characteristics of bilateral market, and it is easy to form a monopoly position of winners, but the implementation of mandatory monopolistic behavior will pose a threat to the diversity elements on which the platform depends, so the E-hailing platform itself not have incentive to implement monopoly. Instead, capital is induced and pressurized by the monopolistic behavior of the platform under the stimulation of profit.

As an economic organization, the E-hailing car platform undertakes the social functions of urban quasi-public transportation supply and coordination. For travelers, more travel options are available. For urban traffic managers, platform-making rules organize loose and diverse market elements and reduce the cost of managing individuals. They do not rely on government subsidies and enrich the supply market through marketization.

Innovative points of this paper include: 1) Emphasis on the individuality and peculiarity of supply-demand relations from the perspective of specific space and time, which differs from traditional price-quantity analysis. 2) Establishing a special supply-demand analysis mechanism on the basis of platform-based distribution system. 3) Combining Information technology with business models with real-time respond to specific demand and a virtual organization with selective rules that diversifies the transport market. 4) Researches on the problems after the implementation of E-hailing policies by local governments and provide an overall management system consisting of ministerial-municipal forces and E-hailing platforms.

\section{References}

1. J. Cramer, A. Krueger, Disruptive Change in the Taxi Business: The Case of Uber. The American Economic Review, 106, 177-182, (2016)

2. L. A. de Souza Silva, M. O. de Andrade, M. L. Alves Maia, How does the ride-hailing systems demand affect individual transport regulation? Research in Transportation Economics, 69, 600-606, (2018)

3. J. V. Hall, A. B. Krueger, An Analysis of the Labor Market for Uber's Driver-Partners in the United States. ILR Review, 71(3), 705-732, (2015)

4. M. Meeker, Internet Trends 2017 - Code Conference, Report: Los Angeles, 355 p., (2017)

5. J. M. Vivoda, A. C. Harmon, G. M. Babulal, B. J. Zikmund-Fisher, E-hail (rideshare) knowledge, use, reliance, and future expectations among older adults. Transportation Research Part F: Traffic Psychology and Behaviour, 55, 426-434, (2018) 
6. J. Wirtz, Uber: Competing as Market Leader in the US versus Being a Distant Second in China. Services Marketing, 626-632, (2016)

7. W. M. Ceng, P. Boutot, Q. Cai, China Travel Industry engine acceleration. Bain \& Company China, Shanghai, (2018)

8. M. Y. Chen, Review and Enlightenment of foreign taxi market regulation. Foreign economy and management, 41-48, (2006)

9. S. Li, Z. Z. Wu, X. L. Wu, Y. Hu, G. He, X. Cheng, F. Song, Z. P. Xie, L. L. Huang, Q. Wang, W. H. Xian, Interpret the Chinese Internet Features: Beijing, Boston Consulting Company, Ali Research Institute, Baidu Development Research Center, Didi Policy Research Institute, (2017)

10. China Internet Network Information Center, 41st China Internet Development Statistical Report: Beijing, 134 p., (2018) 